\title{
Pathways to, and use of, sexual healthcare among Black Caribbean sexual health clinic attendees in England: evidence from cross- sectional bio-behavioural surveys
}

Catherine R. H. Aicken ${ }^{1,3,4^{*}}$ (D), Sonali Wayal ${ }^{1,3}$, Paula B. Blomquist ${ }^{2,3}$, Stella M. Fabiane ${ }^{1,3}$, Makeda Gerressu', Gwenda Hughes ${ }^{2,3,5}$ and Catherine H. Mercer ${ }^{1,3}$

\begin{abstract}
Background: In England, people of Black Caribbean (BC) ethnicity are disproportionately affected by sexually transmitted infections (STI). We examined whether differences in sexual healthcare behaviours contribute to these inequalities.

Methods: We purposively selected 16 sexual health clinics across England with high proportions of attendees of BC ethnicity. During May-September 2016, attendees at these clinics (of all ethnicities) completed an online survey that collected data on health service use and sexual behaviour. We individually linked these data to routinely-collected surveillance data. We then used multivariable logistic regression to compare reported behaviours among BC and White British/Irish (WBI) attendees ( $n=627, n=1411$ respectively) separately for women and men, and to make comparisons by gender within these ethnic groups.

Results: BC women's sexual health clinic attendances were more commonly related to recent bacterial STI diagnoses, compared to WBI women's attendances (adjusted odds ratio, AOR 3.54, 95\% Cl 1.45-8.64, $p=$ 0.009; no gender difference among BC attendees), while BC men were more likely than WBI men (and BC women) to report attending because of a partner's symptoms or diagnosis (AOR 1.82, 95\% Cl 1.14-2.90; AOR BC men compared with $B C$ women: $4.36,95 \%$ Cl 1.42-13.34, $p=0.014$ ). Among symptomatic attendees, $B C$ women were less likely than WBI women to report care-seeking elsewhere before attending the sexual health clinic (AOR 0.60, 95\% Cl 0.38-0.97, $p=0.039$ ). No ethnic differences, or gender differences among BC attendees, were observed in symptom duration, or reporting sex whilst symptomatic. Among those reporting previous diagnoses with or treatment for bacterial STI, no differences were observed in partner notification.

(Continued on next page)
\end{abstract}

\footnotetext{
* Correspondence: c.aicken@ucl.ac.uk

'Centre for Population Research in Sexual Health and HIV, Institute for Global

Health, University College London (UCL), Mortimer Market Centre, London

WC1E 6JB, UK

${ }^{3}$ National Institute for Health Research Health Protection Research Unit (NIHR

HPRU) in Blood Borne and Sexually Transmitted Infections at UCL, in

partnership with PHE, and in collaboration with the London School of

Hygiene \& Tropical Medicine, London, UK

Full list of author information is available at the end of the article
}

(c) The Author(s). 2019 Open Access This article is distributed under the terms of the Creative Commons Attribution 4.0 International License (http://creativecommons.org/licenses/by/4.0/), which permits unrestricted use, distribution, and reproduction in any medium, provided you give appropriate credit to the original author(s) and the source, provide a link to the Creative Commons license, and indicate if changes were made. The Creative Commons Public Domain Dedication waiver (http://creativecommons.org/publicdomain/zero/1.0/) applies to the data made available in this article, unless otherwise stated. 
(Continued from previous page)

Conclusions: Differences in STI diagnosis rates observed between BC and WBI ethnic groups were not explained by the few ethnic differences which we identified in sexual healthcare-seeking and use. As changes take place in service delivery, prompt clinic access must be maintained - and indeed facilitated - for those at greatest risk of STI, regardless of ethnicity.

Keywords: Ethnicity, Black Caribbean, Sexually transmitted infections, Health inequalities, Sexual health clinics, Healthcare behaviour, Health behaviour

\section{Background}

In Britain, people of Black Caribbean (BC) ethnicity are disproportionately affected by sexually transmitted infections (STIs) [1], in the general population $[2,3]$ and in the higher-risk population [4] of sexual health clinic (SHC) attendees [5-8]. BC people attending SHCs are eight times more likely to be diagnosed with gonorrhoea than White British attendees, and almost six times as likely to be diagnosed with syphilis [8]. These health inequalities are not fully explained either at a population level by differences in sexual behaviour or broader contextual factors [1, 3], nor at an individual or partnership level by sexual behavioural and partnership differences among SHC attendees [9].

BC people comprise $1.1 \%$ of England and Wales' population [10]. Migration to the UK from the Caribbean's former British colonies was encouraged during the 1950s and 1960s. The UK's BC communities have been established for several decades, and most of England and Wales' BC population is UKborn [11]. Therefore barriers to healthcare faced by new migrants, e.g. unfamiliarity with the National Health Service (NHS) or language barriers, are likely to be relatively uncommon in the $\mathrm{BC}$ population. However, care-seeking and health behaviours may be influenced by sociocultural [12] and structural factors (including experience of racism) [13].

In the UK, specialist SHCs account for the majority of non-chlamydial STI diagnoses and management [14], providing services to patients on an open-access basis: with no requirement for a referral, and irrespective of where they live. Primary care services (e.g. general practice) provide variable, non-specialist sexual healthcare to local populations [15-17]. Rapid access to STI testing for those at risk of STI, and rapid treatment and partner notification support for those diagnosed, can prevent onward transmission of STIs and harms associated with long-term infection [18, 19]. The individual and public health effectiveness of STI services is influenced by whether they are used by those at risk of STI, how promptly they are used, and whether those infected notify partners and abstain from sex until treatment completion.
The sexual healthcare behaviour of people of $\mathrm{BC}$ ethnicity in the UK is under-researched: a recent systematic review found few studies which focus on this topic [1]. Nationally-representative data from Britain's general population (collected 2010-12) show that BC men and women were more likely to report SHC attendance within the previous 5 years than White British men and women, after adjusting for confounders [3]. In a 2004-5 survey in SHCs across England, symptomatic BC men (but not women) experienced less provider-delay in accessing clinics than symptomatic White men did, but no other statistically-significant differences were observed in either care-seeking, or in sexual behaviour since seeking care [20]. Access to SHCs has changed since then: patients' pathways to clinic shortened between 2004 and 5 and 2009 [17], but subsequently may have lengthened [21]. We conjectured that ethnic differences in pathways to, and use of, SHCs, might exist and contribute to explaining the high STI diagnosis rates among $\mathrm{BC} \mathrm{SHC}$ attendees. To explore this, we compared sexual healthcare seeking and use (hereafter, 'sexual healthcare behaviours') among BC and White British/Irish (WBI) attendees (the ethnic majority). We also compared sexual healthcare behaviours by gender, within these ethnic groups.

\section{Methods \\ Study design, study population and sampling}

We developed a Bio-Behavioural Enhanced Surveillance Tool (BBEST) to explore factors influencing STI among key risk groups [22]. Development of the BBEST included formative qualitative research with $B C$ people [23], stakeholder engagement (which continued throughout the study) and piloting [22]. We purposively-selected $16 \mathrm{SHCs}$ across England with high proportions of $\mathrm{BC}$ attendees. Between May and September 2016, people attending these clinics (of all ethnicities) were invited to complete the BBEST online survey (Additional file 6), which they accessed on tablets provided at the clinics, or their own devices. Screening questions routed eligible attendees (aged $\geq 15$ years old and sexually-active in the past year) to the full survey, which included questions about sexual 
health service use, symptoms, sexual behaviour whilst symptomatic, and partner notification. ${ }^{1}$ Survey data were individually linked, with participants' consent, to an extract of data routinely collected by SHCs for national STI surveillance (GUMCAD STI Surveillance System), including STI diagnoses. We restricted our analyses to the $627 \mathrm{BC}$ and $1411 \mathrm{WBI}$ attendees (99.4\%) who gave their gender as male or female. (We present findings for other ethnic groups in Additional files 1, 3, 4 and 5). These sample sizes gave us adequate statistical power $(80 \%)$ to detect as statistically significant (at the $5 \%$ level) differences by ethnic group (BC vs. WBI) of, for example, $5 \%$ vs. $12 \%$ among men and $5 \%$ vs. $11 \%$ among women (i.e. for behaviours with low prevalence), and differences by ethnic group (BC vs. WBI) of, for example, $40 \%$ vs. $53 \%$ among men and $40 \%$ vs. $52 \%$ among women (i.e. for more prevalent behaviours). These power calculations also allow for a design effect of 1.2, reflecting how participants were clustered by clinic.

\section{Data analysis}

Data were analysed using STATA v14, using survey commands to take account of the clustering of participants by clinic. We stratified the data by gender, and used logistic regression to obtain crude odds ratios (ORs) comparing BC and WBI participants. We then stratified by these two ethnic groups, and used logistic regression to compare participants by gender. We used multivariable logistic regression to account for possible confounders, separately for each comparison, using saturated models. Statistical significance was considered as $p<0.05$ for all analyses.

In our analysis of reasons for SHC attendance, we examined reasons for attendance that participants reported in the survey, and used clinical data to identify participants with recent STI diagnoses (within the 6 weeks prior to their attendance at which the survey was completed) which we considered very probably related to clinic attendance. ${ }^{2}$

\section{Ethics}

This study was approved by the NRES Committee South Central - Oxford C, ref.: 15/SC/0223.

\section{Results}

\section{Sample characteristics}

Table 1 presents participants' characteristics, and comparisons by ethnic group and gender (findings for a wider range

\footnotetext{
${ }^{1}$ Throughout this paper we use the terms partner/partnership to refer to sexual partners/partnerships, regardless of their duration, or romantic or social significance.

${ }^{2}$ The survey question on reasons for clinic attendance did not include a response option for recent diagnosis or attendance for treatment.
}

of ethnic groups are presented in Additional file 1). In this section and throughout the text of the Results, we first comment on ethnic differences among women, then among men, and finally, gender differences among $\mathrm{BC}$ participants.

$\mathrm{BC}$ and WBI women were similar in age (medians 26 , 25 years respectively). $23.0 \%$ of $\mathrm{BC}$ and $8.8 \%$ of WBI women were born outside the UK. BC women were less likely than WBI women to be educated beyond GCSEs (77.6, $84.9 \%$, respectively), but equally likely to be in work (just over 70\%). Slightly more BC women than WBI women self-identified as heterosexual (94.3, 92.4\% respectively). $\mathrm{BC}$ women reported fewer partners than WBI women: e.g. $8.5 \% \mathrm{BC}$ women, compared with $17.3 \%$ WBI women, reported 5 or more partners within the past year. BC women were also less likely to report new partners in this timeframe. However, there were no ethnic differences in women's current partnership type(s). There were also no ethnic differences in the proportions of women: reporting condomless last sex (around 70\%), or considering themselves at risk of STI (around 44\%).

Over a third (35.3\%) of BC men were aged under 25, compared with $26.7 \%$ WBI men. $20.6 \%$ of BC men were born outside the UK, compared with 9.5\% WBI men. A lower proportion of $\mathrm{BC}$ men than WBI men were educated beyond GCSEs (68.8, 83.8\% respectively), and a lower proportion were in work $(73.9,83.1 \%)$. In our sample, $87.7 \%$ BC men self-defined as heterosexual, compared with $75.4 \%$ WBI men. ${ }^{3}$ No ethnic differences were observed in the number of partners men had in the past year; around $39 \%$ reported 5 or more partners, and almost $83 \%$ reported new partners. While there were no ethnic differences in the proportions of men reporting no current partnership, current steady or casual partnerships, 35.2\% BC men reported uncommitted regular partnerships, compared with $21.5 \%$ WBI men. There were no ethnic differences in the proportions of men reporting condomless last sex (around 65\%), nor in the proportions considering themselves at risk of STI (just over 70\%).

$\mathrm{BC}$ men were somewhat older than $\mathrm{BC}$ women (OR for being age 25 or older: 1.52, 95\% CI: 1.02-2.25). While there were no gender differences observed in the proportions of $\mathrm{BC}$ attendees born outside the $\mathrm{UK}$, nor the proportions in employment, a lower proportion of $\mathrm{BC}$ men than $\mathrm{BC}$ women were educated beyond GCSEs (OR 0.64, 95\% CI:0.46-0.89). Despite our survey slightly under-sampling $\mathrm{MSM}^{2}{ }^{2} \mathrm{BC}$ men were more likely than $\mathrm{BC}$ women to self-identify as non-heterosexual (OR 2.29, 95\%CI:1.04-5.03). BC men reported more partners in the past 12 months than $\mathrm{BC}$ women (OR for $>1$ partner, vs. 1 partner: 5.08, 95\% CI:2.88-8.97; OR for $\geq 5$ partners, vs. $<5$ partners: 6.75 , 95\% CI:4.08-11.17), and were more

\footnotetext{
${ }^{3}$ See footnote $\mathrm{b}$ to Table 1 .
} 


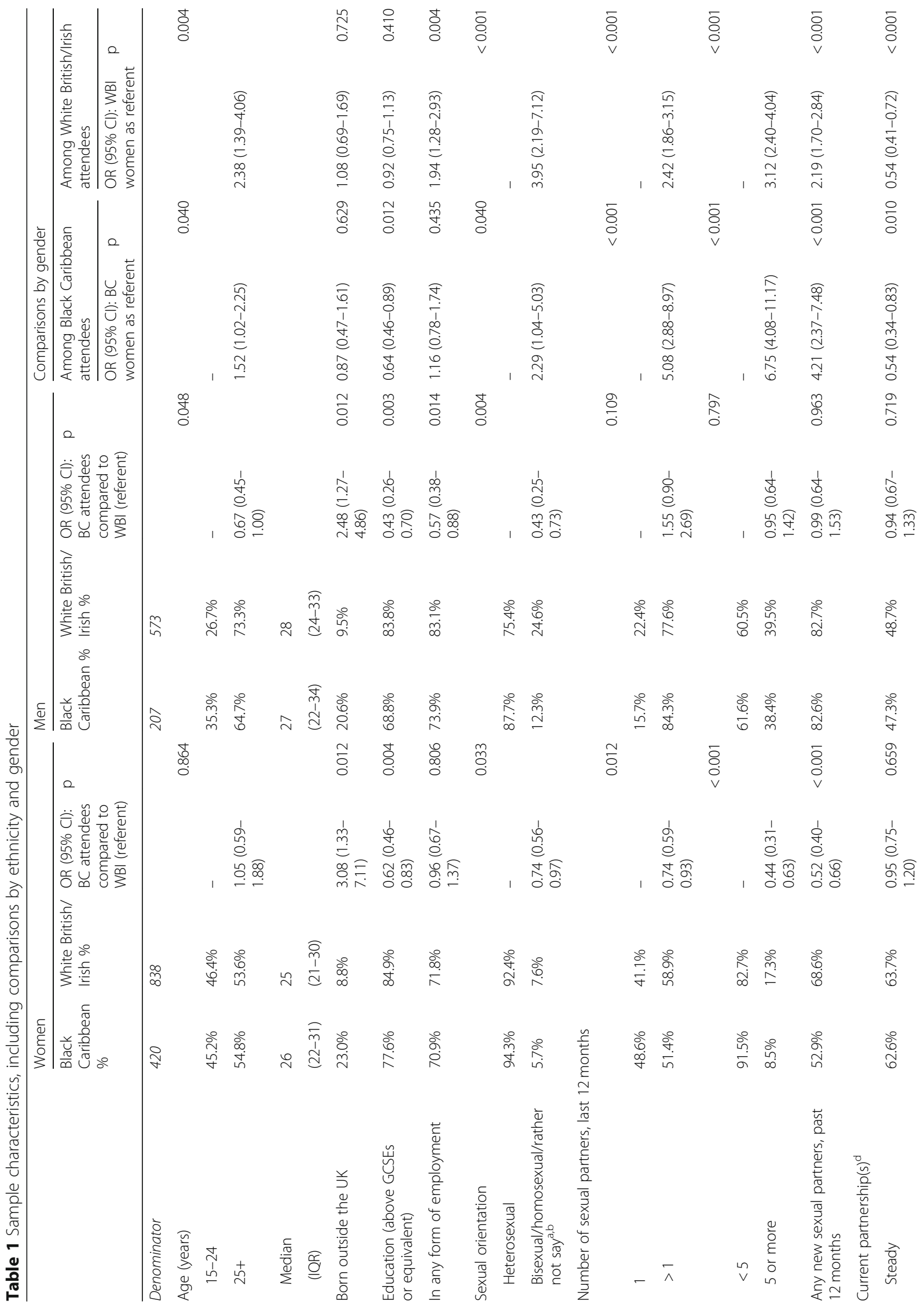




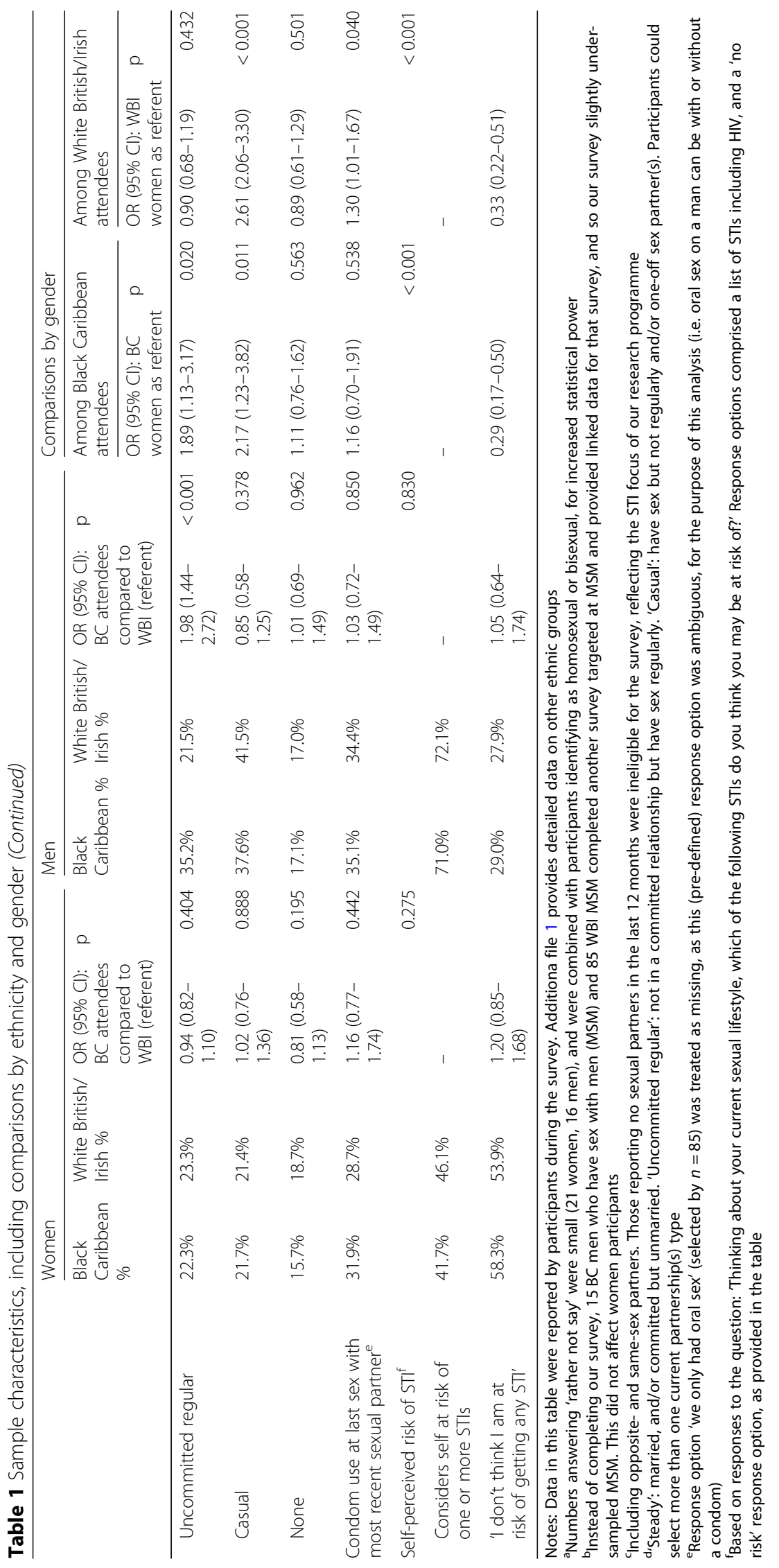


likely to report new partner(s) (OR 4.21, 95\% CI: 2.37-7.48). Although there were no gender differences among $\mathrm{BC}$ attendees in the proportions reporting no current partnerships, there were differences in current partnership types: a lower proportion of $\mathrm{BC}$ men than $\mathrm{BC}$ women reported being in steady partnership(s) (OR: 0.54, 95\%CI:0.34-0.83), while a higher proportion reported uncommitted regular, or casual, partnership(s) (ORs: uncommitted regular: 1.89, 95\% CI:1.13-3.17; casual: 2.17, 95\% CI: 1.23-3.82). There was no gender difference in reporting condomless last sex, but $\mathrm{BC}$ men were more likely than $\mathrm{BC}$ women to consider themselves at risk of STI (OR for considering not at risk of STI: 0.29, 95\% CI:0.17-0.50).

\section{Reasons for attending SHCs}

The two main reasons for attending clinic were having (had) symptoms, and wanting an asymptomatic check-up, together reported by almost three-quarters of attendees. After adjusting for variables which were statistically significant in Table 1, BC women's attendance was more likely to be related to recent STI diagnosis/es, than WBI women's, and specifically bacterial STI diagnosis/es (AOR 2.98, 95\% CI:1.43-6.23; 4.1\% BC and 1.3\% WBI women had recent bacterial STI diagnosis/es). BC women were more likely than WBI women to report attending because they were contacted by the clinic (AOR 3.64, 95\% CI: 1.41-9.38), but less likely to report attending for a contraceptive or reproductive health reason (AOR 0.64, 95\% CI: $0.45-0.92$ ). No other ethnic differences were observed in women's reasons for attendance (Fig. 1, data presented in Additional file 2). (Additional file 3 presents findings for a wider range of ethnic groups).

Among men, no statistically-significant ethnic differences were observed in the proportions with recent STI diagnosis/es, nor in reported reasons for attendance, except that $\mathrm{BC}$ men were more likely to report attending because of a partner's symptoms or STI diagnosis (AOR 1.81, 95\%CI:1.18-2.79).

Among $\mathrm{BC}$ attendees, no gender differences were observed in recent STI diagnoses. The only reasons for attendance which differed by gender were: partner's symptoms/diagnosis (more commonly-reported by BC men than BC women, AOR: 4.36, 95\% CI:1.42-13.34); and contraceptive/reproductive health reasons (unsurprisingly much less commonly-reported by $\mathrm{BC}$ men than BC women, AOR 0.04, 95\% CI:<0.01-0.70).

\section{Symptomatic attendees' pathways to clinic}

We now focus on the pathways to clinic of participants who reported being symptomatic as a reason for attendance, around four-in-ten of the sample (Table 2;
Additional file 4 presents findings for a wider range of ethnic groups).

Around a third of symptomatic women reported symptom onset within the last 7 days, and around half reported having had sex since symptoms began, with no ethnic differences observed. Symptomatic BC women were less likely than their WBI counterparts to report having tried to get treatment/advice elsewhere before attending clinic (AOR: 0.60, 95\% CI: 0.38-0.97). No ethnic differences were observed among symptomatic men, in reporting: duration of symptoms, seeking treatment/advice elsewhere before attending clinic, or sex since symptoms began. No gender differences in these variables were observed among symptomatic BC attendees.

\section{Attendees' previous experiences of STI and partner notification}

We now focus on the subsample of attendees reporting previous STI diagnosis or treatment (hereafter 'previous STI'), exploring their most recent episode (Table 3; Additional file 5 presents findings for a wider range of ethnic groups). Previous STI was more commonly reported by BC women than WBI women $(61.2 \%$ compared with $40.0 \%$ ), with a smaller difference between BC and WBI men (60.9, 50.6\% respectively), and no gender difference among $\mathrm{BC}$ attendees.

Almost half of attendees reporting previous STI were last diagnosed or treated within the past year, with no differences by gender or ethnic group. $\mathrm{BC}$ women and $\mathrm{BC}$ men were more likely than their WBI counterparts to report that their most recent episode included bacterial STI(s) and/or TV (AORs: women: 1.97, 95\% CI:1.52-2.55; men: 3.37, 95\% CI:2.17-5.24). No statistically-significant gender differences were observed among BC attendees.

Of those reporting that their most recent STI was bacterial or TV, four-fifths recalled that clinic staff advised partner notification (PN), with no ethnic or gender differences. No ethnic differences were observed in the proportion of women reporting notifying all their partners (around four-fifths). However, BC men were more likely than WBI men to report notifying all of their partners (AOR for not notifying all partners, or cannot remember: 0.30, 95\%CI:0.14-0.67). No gender differences in reporting this were observed among $\mathrm{BC}$ attendees.

Among those reporting notifying any partner(s) at this time, two-thirds reported notifying partner(s) in person, and half reporting doing so by telephone, text message, email, or social media (combined). Less than $4 \%$ had clinic staff notify partners for them. No ethnic or gender differences in notification methods were observed.

The three most commonly-reported reasons for not notifying (all) partners were similar between ethnic groups (however denominators were small). BC attendees of both 


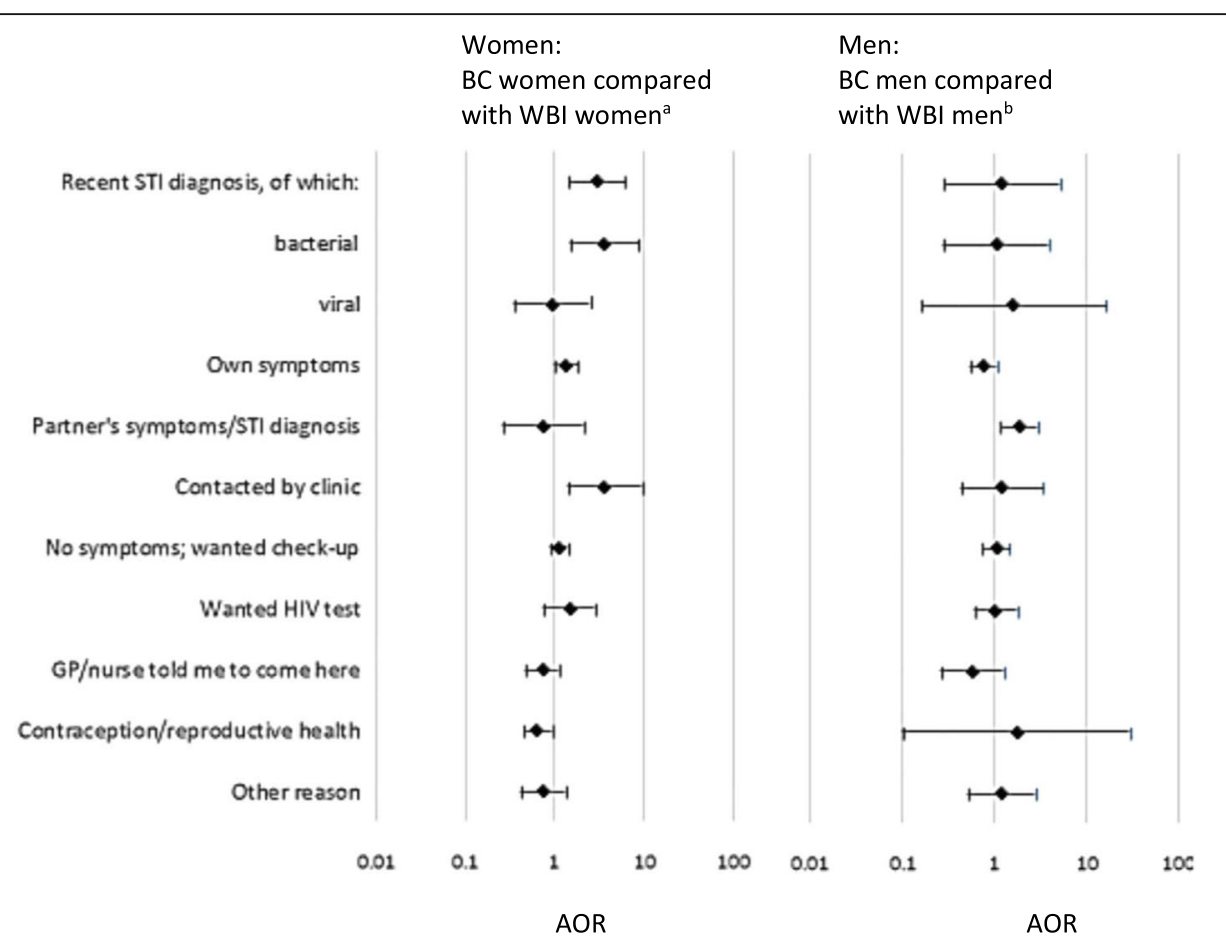

Fig. 1 Comparison of reasons for attendance, by ethnic group. Multiple reasons could apply. Adjusted Odds Ratios, adjusted for variables which were statistically significant at $p<0.05$ in Table $1 .{ }^{a}$ For the ethnic comparison among women: the following binary variables: born in UK, education, sexual orientation, >5/5+ partners in past 12 months (other sexual partner number variables were omitted due to likely covariance). ${ }^{b}$ For the ethnic comparison among men: age as a continuous variable, and the following binary variables: born in UK, education, employment, sexual orientation, reporting regular but uncommitted partner(s). Additional file 2 provides the data used in Fig. 1 including within ethnic group comparisons by gender, and Additional file 3 provides detailed data on other ethnic groups

genders reported being scared to tell partners (and BC men, being worried that their partner would leave them), which did not feature in WBI attendees' top-3 reasons.

\section{Discussion}

\section{Main findings}

Our study showed that differences in STI diagnosis rates observed between BC and WBI ethnic groups were not explained by the few ethnic differences that were identified in sexual healthcare-seeking. These differences were that $\mathrm{BC}$ women were more likely than WBI women to have had recent bacterial STI diagnosis/es, or to attend because they were contacted by the clinic, while $\mathrm{BC}$ men were more likely than WBI men to report attendance due to a partner's diagnosis. Symptom duration was similar between ethnic groups, but symptomatic BC women were less likely than symptomatic WBI women to report first seeking care elsewhere. We observed no ethnic differences in symptomatic attendees' likelihood of reporting sex since symptom onset. Among those who had previously been diagnosed/treated for bacterial STI(s) or TV, there were no ethnic differences in reporting having been advised to notify partners, but BC men were more likely than WBI men to report notifying all of their partners at this time.

\section{Strengths and limitations}

Our research follows recommendations to assess needs and inequalities by ethnicity, to guide practical action [25], and contributes findings about an epidemiologicallyimportant population. Purposively-selecting clinics with high proportions of $\mathrm{BC}$ attendees enabled us to recruit a sample that included a relatively large number of this minority group. This enabled us to perform adjusted analyses (which were not done in a previous, similar study [20]) to control for observed differences in sociodemographic and sexual behavioural factors, which could otherwise obscure associations with health (care) behaviours. As others have done, we made gender-stratified comparisons by ethnicity [20], but additionally conducted ethnicity-stratified comparisons by gender, to explore the 'effect' of gender within ethnic groups.

Our findings are derived from detailed data collected at SHCs across England. Linkage to clinical data (achieved for the majority of survey-completers [22]) enabled inclusion of clinic-verified STI diagnoses. This has been done in previous studies of patients' pathways to clinic $[17,26,27]$, but we were able to link to longitudinal clinical data, to include STI diagnoses associated with earlier or later attendances at the same clinic. While it is not possible to link diagnoses made in different clinics 


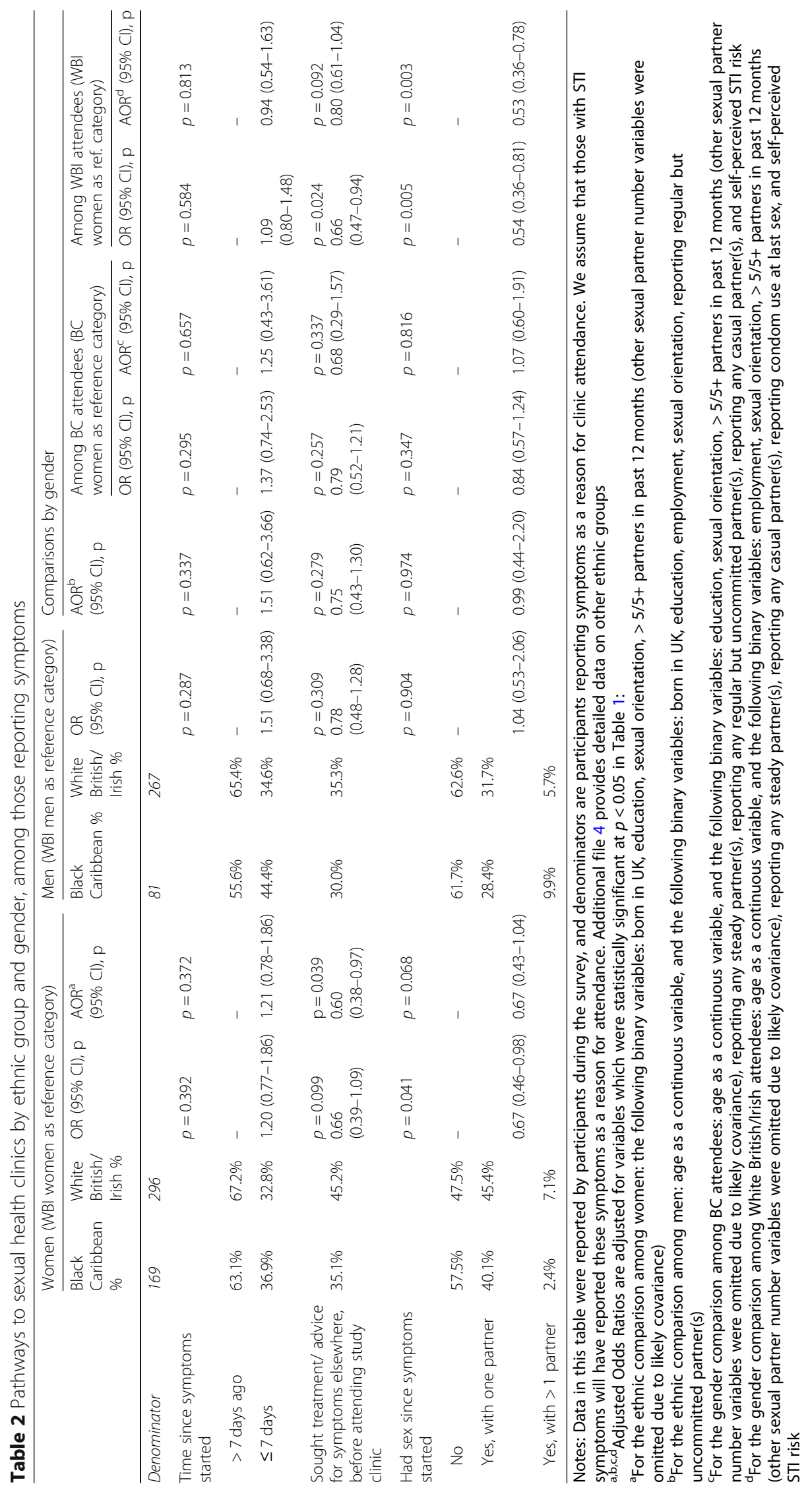


Sicken et al. BMC Health Services Research

(2019) 19:668

Page 9 of 13

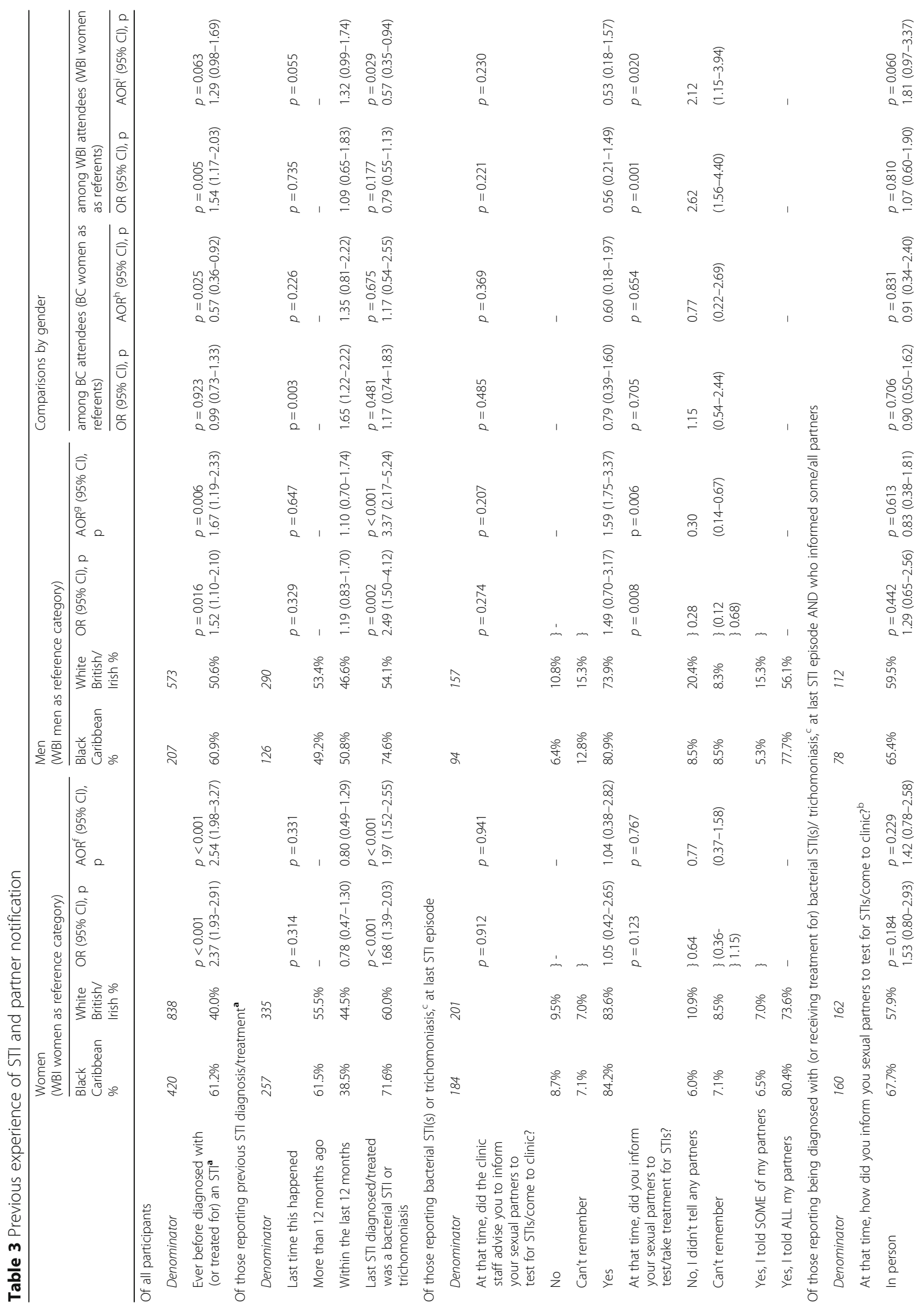




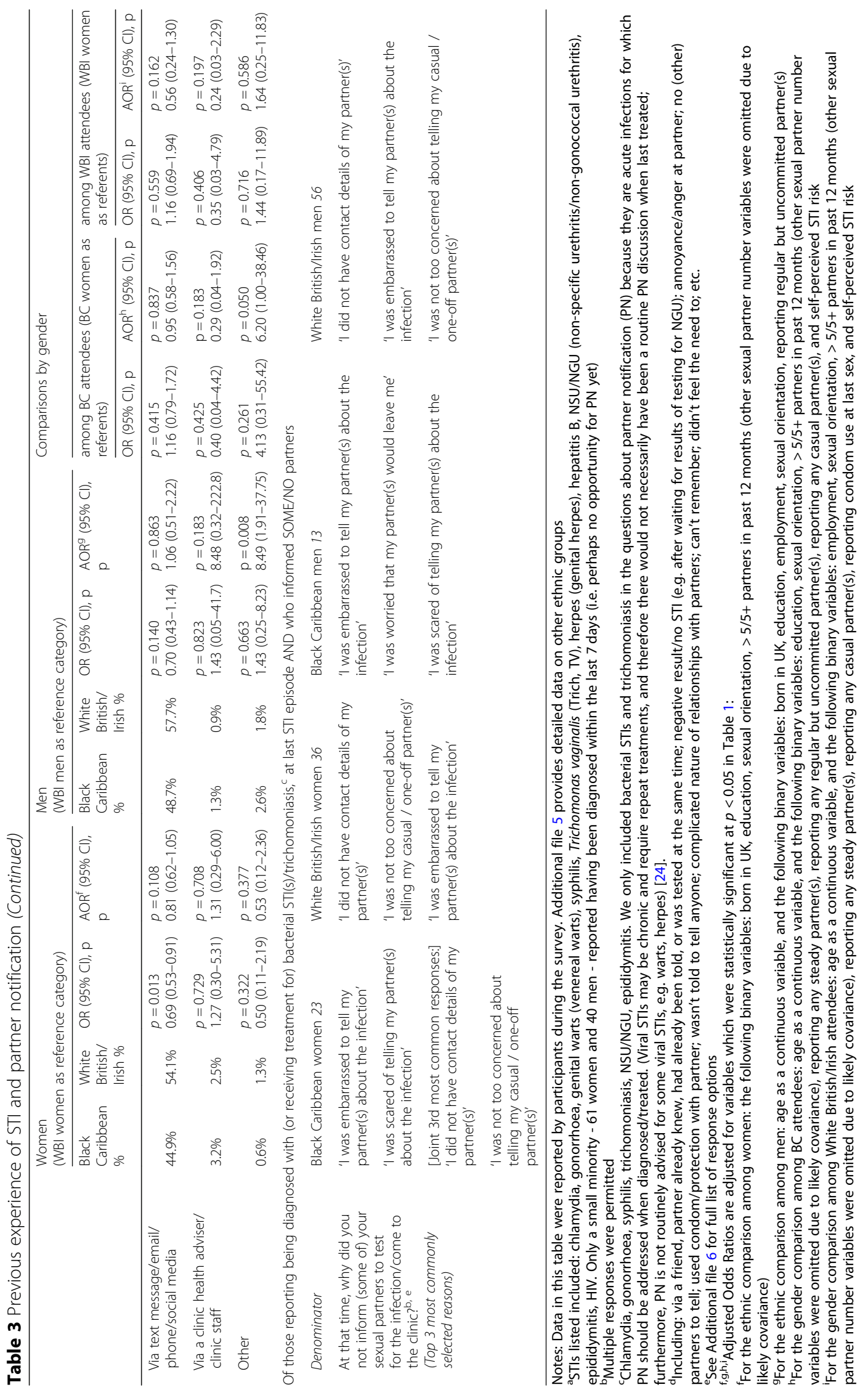


(because patient identifiers are clinic-specific), our use of a narrow (+/ 6 weeks) 'window' for diagnoses data probably minimises the impact of this issue.

By surveying SHC attenders, we focus on a high STI risk population [4], with a key role in STI transmission and control. However, we were unable to collect data on those who did not use SHCs, and so do not know about non-attenders care-seeking or use of other services. In nationally-representative survey data, over $85 \%$ people who did not attend SHC in the past year, reported unsafe sex during this period [28]. Non-attenders also reported fewer markers of STI risk than attendees (after age-adjustment) [28], but nevertheless include people who are underserved, and thus epidemiologically-important.

Our analyses of sub-samples (e.g. Table 3) may have lacked the statistical power to detect some differences as significant, reflecting how we sought to examine ethnic differences within gender, and gender differences within ethnic group, which our original power calculations did not factor in. Our sampling strategy was designed to obtain sufficient numbers of SHC attendees of $\mathrm{BC}$ ethnicity, a relatively under-researched group. It was not designed to give us sufficient statistical power to additionally stratify our analyses by sexual orientation, and so we were unable to explore reasons why differences exist by sexual orientation, although these have been the focus of other studies $[15,28,29]$. Survey response rates were generally high (averaging $62.2 \%$ ), but varied by clinic, related to clinics' ability to support survey administration [22]. Among survey-completers, consent to data linkage was slightly lower among $\mathrm{BC}$ than White participants $(87.1 \%$ vs. $93.8 \%, p<0.01)$ [22]. This is still relatively high, which minimises any differential influence on representativeness by ethnicity. We found some evidence that we may have over-sampled those with higher risk-profiles than SHC attendees in general [22]. The effect on our findings is unknown, but the highest-risk individuals are those of greatest concern in terms of individual and public health need.

All self-reported data is potentially subject to social desirability bias, but confidential, electronic self-completion may reduce this $[30,31]$. Sexual health knowledge may differ by ethnicity (suggested by large survey of London young people [32]), which could influence actual and reported behaviours, and ethnic differences therein.

\section{Discussion of findings in relation to other research}

Our sample of BC SHC attendees is likely to be at higher STI risk than the $\mathrm{BC}$ population as a whole [33], or the general population [4]. We found ethnic differences in reasons for attendance, whereas no differences were observed in a 2004-05 clinic survey
[20], possibly related to statistical power, and plausibly influenced by SHCs' accessibility at the time. Nevertheless, our findings are similar to this earlier survey in that we found few ethnic differences in sexual healthcare-seeking behaviours, despite observing differences in STI diagnosis [20].

\section{Meaning and implications}

Differences in STI diagnosis rates observed between BC and WBI ethnic groups [14] are unlikely to be explained by the few differences identified in sexual healthcareseeking and use, according to our study of SHC attendees. In the context of persistent elevated STI risk among England's (and Britain's) BC population [3, 14], we need to ensure their access to sexual healthcare is, at the very least, maintained, if not improved. In terms of STI control, it is encouraging that we found that symptomatic $\mathrm{BC}$ women attendees were less likely than WBI women to seek care elsewhere before attending a SHC, because using other services may lengthen care-seeking $[17,27]$. It is also encouraging that among those with previous bacterial STI/TV, a higher proportion of BC men than WBI men reported notifying all partners. Yet there is scope to improve such behaviours among all ethnicities, through clinic-based and broader health promotion and structural interventions. It is concerning that $\mathrm{BC}$ and WBI women attendees were equally likely to perceive themselves at risk of STI, given $\mathrm{BC}$ women attendees' greater likelihood of diagnosis. In a separate analysis of our dataset, heterosexual BC women reported lower recent partner numbers than their WBI counterparts [9], and this lower individual risk behaviour may affect risk perception. However, the picture is complex, with survey data from the general population suggesting little relationship between STI risk perception and both reported unsafe sexual behaviour, and engagement with sexual healthcare [34]. Greater engagement with asymptomatic check-ups is needed, among sexually-active people who are at elevated risk of STI who do not test for STIs, in line with Public Health England's advice [14].

Since data collection, funding cuts [35] and SHC closures have taken place in England, including some clinics which participated in this study. STI testing across London became accessible online, with an expectation that a significant proportion of patients could test using home self-sampling packs [36]. The effect of these changes on the $4.2 \%$ of Londoners of $\mathrm{BC}$ ethnicity [10] is unknown; generally, evidence about e-health use by ethnicity is lacking [37]. Evaluation of sexual health service reconfigurations must address impacts on access by ethnicity, to ensure that service changes lessen, or at the very least do not exacerbate, existing health inequalities. 


\section{Conclusions}

Although BC people in England are at elevated risk of STI, this elevated risk is unlikely to be explained by differences in sexual healthcare-seeking and use, among those accessing clinics. We found that these behaviours were similar between BC attendees and the WBI ethnic majority. However, differences in reasons for attendance require further exploration, including by using qualitative research methods to unpack the quantitative differences our study has identified, as do the sexual healthcare behaviours of people who do not access SHCs.

\section{Additional files}

Additional file 1: Version of Table 1., showing data for a wider range of ethnic groups (DOCX $28 \mathrm{~kb}$ )

Additional file 2: Data for Figure 1. (DOCX $17 \mathrm{~kb}$ )

Additional file 3: Version of Figure 1.'s data, showing data for a wider range of ethnic groups (DOCX $17 \mathrm{~kb}$ )

Additional file 4: Version of Table 2., showing data for a wider range of ethnic groups (DOCX $17 \mathrm{~kb}$ )

Additional file 5: Version of Table 3., showing data for a wider range of ethnic groups (DOCX $34 \mathrm{~kb}$ )

Additional file 6: Text of the online survey (PDF $740 \mathrm{~kb}$ )

\section{Abbreviations}

95\% Cl: 95\% confidence interval; AOR: Adjusted odd ratio; BBEST: The Bio-Behavioural Enhanced Surveillance Tool (which our research team developed, and which was used to collect data for the current study); BC: Black Caribbean; NHS: National Health Service; OR: Odds ratio; PN: Partner notification; SHC: Sexual health clinic; STI: Sexually transmitted infection; TV: Trichomonas vaginalis; UK: United Kingdom; WBI: White British or Irish

\section{Acknowledgements}

We thank all of the study participants and staff of the SHCs involved in this study. We acknowledge the National Institute of Health Research Health Protection Research Unit (NIHR HPRU) in Blood Borne and Sexually Transmitted Infections Steering Committee: Caroline Sabin (Director), Anthony Nardone (PHE lead), Catherine Mercer, Gwenda Hughes, Greta Rait, Jackie Cassell, William Rosenberg, Tim Rhodes, Kholoud Porter, Sema Mandal and Samreen ljaz, and the members of Theme A of the NIHR HPRU in Blood Borne and Sexually Transmitted Infections Steering Committee: Catherine Mercer, Gwenda Hughes, Hamish Mohammed, Jackie Cassell, Fiona Burns, Makeda Gerressu, Jonathan Elford, David Phillips, Gary Brook, Nicola Low, Anthony Nardone, Sarika Desai, Adamma Aghaizu, Alison Rodgers, and Paul Crook. We also thank Laura Tickle, Sexual Health Adviser, for a helpful discussion about interpretation of survey responses.

\section{Authors' contributions}

CA and CHM conceived the paper, and CA drafted it. SW was the study co-ordinator for the BBEST study, responsible for developing the survey, and seeking ethics and R\&D approvals. She was also responsible for overseeing survey implementation at all study sites, with the help of $\mathrm{PB}$, who performed the linkage between survey and GUMCAD data. Plans for this article's analysis were refined in discussions between CA, SW, CHM, MG and GH. CA and SF conducted the statistical analyses, with CHM. CHM and GH lead the Health Protection Research Unit in Blood-borne and Sexually Transmitted Infections Theme A: Understanding Risk and Reduction for STIs and Blood Borne Viruses, within which this study was conducted. All authors contributed to subsequent re-drafting of the manuscript and approved the final version.

\section{Funding}

This work was supported by the National Institute for Health Research Health Protection Research Units (NIHR HPRU) funding programme, which funded the NIHR HPRU in Blood Borne and Sexually Transmitted Infections at UCL in partnership with Public Health England (PHE) and in collaboration with the London School of Hygiene and Tropical Medicine, within which this study was undertaken. The views expressed in this publication are those of the author(s) and not necessarily those of the NHS, the National Institute for Health Research, the Department of Health, or Public Health England. The funding body had no role in the design of the study; or in the collection, analysis, or interpretation of the data; or in writing the manuscript.

\section{Availability of data and materials}

The text of our online survey is provided in Additional file 6.

The data that support the findings of this study are available from University College London ( $U C L)$ but restrictions apply to the availability of these data, which were used under license for the current study, and so are not publicly available. Data are however available from the authors upon reasonable request and with permission of Public Health England.

\section{Ethics approval and consent to participate}

This study was approved by the National Research Ethics Service (NRES) Committee South Central - Oxford C, ref.: 15/SC/0223. In the online survey, participants were asked to indicate their informed consent to participation, and, separately, whether they additionally agreed to linkage of their survey data to existing routinely collected data on STI diagnosis and testing.

\section{Consent for publication}

Not applicable, as we present no data at the individual level.

\section{Competing interests}

The authors declare that they have no competing interests.

\section{Author details}

${ }^{1}$ Centre for Population Research in Sexual Health and HIV, Institute for Global Health, University College London (UCL), Mortimer Market Centre, London WC1E 6JB, UK. ${ }^{2}$ HIV \& STI Department, Centre for Infectious Disease Surveillance and Control, Public Health England (PHE), 61 Colindale Ave, London NW9 5EQ, UK. ${ }^{3}$ National Institute for Health Research Health Protection Research Unit (NIHR HPRU) in Blood Borne and Sexually Transmitted Infections at UCL, in partnership with PHE, and in collaboration with the London School of Hygiene \& Tropical Medicine, London, UK. ${ }^{4}$ School of Health Sciences, University of Brighton, Village Way, Falmer, Brighton BN1 9PH, UK. Instituto de Medicina Tropical, Universidade de São Paulo, São Paulo, Brazil.

Received: 27 November 2018 Accepted: 1 August 2019

Published online: 18 September 2019

\section{References}

1. Wayal S, Aicken $\mathrm{CRH}$, Griffiths C, Blomquist PB, Hughes G, Mercer $\mathrm{CH}$. Understanding the burden of bacterial sexually transmitted infections and trichomonas vaginalis among black Caribbeans in the United Kingdom: findings from a systematic review. PLoS One. 2018;13(12):e0208315.

2. Fenton KA, Mercer CH, McManus S, Erens B, Wellings K, Macdowall W, et al. Ethnic variations in sexual behaviour in Great Britain and risk of sexually transmitted infections: a probability survey. Lancet. 2005;365(9466):1246-55.

3. Wayal S, Hughes G, Sonnenberg P, Mohammed H, Copas AJ, Gerressu M, et al. Ethnic variations in sexual behaviours and sexual health markers: findings from the third British National Survey of sexual attitudes and lifestyles (Natsal-3). Lancet Public Health. 2017;2(10):e458-e72.

4. Sonnenberg P, Clifton S, Beddows S, Field N, Soldan K, Tanton C, et al. Prevalence, risk factors, and uptake of interventions for sexually transmitted infections in Britain: findings from the National Surveys of sexual attitudes and lifestyles (Natsal). Lancet. 2013;382(9907):1795-806.

5. Evans B, Bond R, MacRae K. Rates of gonorrhoea and chlamydia in black ethnic groups. Sex Transm Infect. 2001 Oct;77(5):390-1.

6. Low N, Sterne JA, Barlow D. Inequalities in rates of gonorrhoea and chlamydia between black ethnic groups in south East London: cross sectional study. Sex Transm Infect. 2001;77(1):15-20.

7. Hughes G, Andrews N, Catchpole M, Goldman M, Forsyth-Benson D, Bond $M$, et al. Investigation of the increased incidence of gonorrhoea diagnosed in genitourinary medicine clinics in England, 1994-6. Sex Transm Infect. 2000;76(1):18-24. 
8. Furegato M, Chen Y, Mohammed H, Mercer CH, Savage EJ, Hughes G. Examining the role of socioeconomic deprivation in ethnic differences in sexually transmitted infection diagnosis rates in England: evidence from surveillance data. Epidemiol Infect. 2016;144(15):3253-62.

9. Aicken C, Wayal S, Blomquist P, Fabiane S, Gerressu M, Hughes G, et al. Ethnic variations in sexual partnerships and mixing, and their association with STI diagnosis: findings from a cross-sectional bio-behavioural survey of attendees of sexual health clinics across England. Sex Transm Infect. In press. 2019. https://doi.org/10.1136/sextrans-2018-053739.

10. Ethnicity and national identity in England and Wales: 2011. Office for National Statistics; 2012.

11. 2011 Census analysis: ethnicity and religion of the non-UK born population in England and Wales: 2011. Office for National Statistics; 2015.

12. Connell P, McKevitt C, Low N. Sexually transmitted infections among black young people in south-East London: results of a rapid ethnographic assessment. Cult Health Sex. 2001;3(3):311-27.

13. Karlsen S, Nazroo JY. Agency and structure: the impact of ethnic identity and racism on the health of ethnic minority people. Sociol Health IIIn. 2002;24(1):1-20

14. PHE. Sexually transmitted infections and screening for chlamydia in England, 2018. Health Protection Report, Public Health England. 2019;13(19)1-38. Public Health England (PHE) publications gateway number: 2018819

15. Clifton S, Mercer CH, Woodhall SC, Sonnenberg P, Field N, Lu L, et al. Patterns of chlamydia testing in different settings and implications for wider STI diagnosis and care: a probability sample survey of the British population. Sex Transm Infect. 2016;93:276-83.

16. Mercer CH, Aicken CR, Cassell JA, Hartnell V, Davies L, Ryan J, et al. Not so different after all? Comparing patients attending general practice-based locally enhanced services for sexual health with patients attending genitourinary medicine. Int J STD AIDS. 2013;24(2):106-11.

17. Mercer CH, Aicken CR, Estcourt CS, Keane F, Brook G, Rait G, et al. Building the bypass--implications of improved access to sexual healthcare: evidence from surveys of patients attending contrasting genitourinary medicine clinics across England in 2004/2005 and 2009. Sex Transm Infect. 2012;88(1):9-15.

18. White PJ, Ward H, Cassell JA, Mercer CH, Garnett GP. Vicious and virtuous circles in the dynamics of infectious disease and the provision of health care: gonorrhea in Britain as an example. J Infect Dis. 2005;192(5):824-36.

19. Mathews C, Coetzee N. Partner notification. Clin Evid. 2009;2009:1605.

20. Gerressu M, Mercer CH, Cassell JA, Brook G, Dave S. The importance of distinguishing between black Caribbeans and Africans in understanding sexual risk and care-seeking behaviours for sexually transmitted infections: evidence from a large survey of people attending genitourinary medicine clinics in England. J Public Health. 2012;34(3):411-20.

21. Prescott T, Hayden V, Foley E. Access to GUM clinics in the UK - a worsening picture? Sex Transm Infect. 2015;91(suppl.1):A6.

22. Wayal S, Reid D, Blomquist PB, Weatherburn P, Mercer CH, Hughes G. The acceptability and feasibility of implementing a bio-behavioral enhanced surveillance tool for sexually transmitted infections in England: mixedmethods study. JMIR Public Health Surveill. 2018;4(2):e52.

23. Wayal S, Gerressu M, Weatherburn P, Gilbart V, Hughes G, Mercer CH. A qualitative study of attitudes towards, typologies, and drivers of concurrent partnerships among people of black Caribbean ethnicity in England and their implications for STI prevention. BMC Public Health. In press.

24. McClean H, Radcliffe K, Sullivan A, Ahmed-Jushuf I. 2012 BASHH statement on partner notification for sexually transmissible infections. Int J STD AIDS. 2013;24(4):253-61.

25. Bhopal R. Is research into ethnicity and health racist, unsound, or important science? BMJ. 1997;314(7096):1751-6.

26. Aicken CR, Cassell JA, Estcourt CS, Keane F, Brook G, Rait G, et al. Rationale and development of a survey tool for describing and auditing the composition of, and flows between, specialist and community clinical services for sexually transmitted infections. BMC Health Serv Res. 2011;11(30).

27. Mercer $\mathrm{CH}$, Sutcliffe L, Johnson AM, White PJ, Brook G, Ross JDC, et al. How much do delayed healthcare seeking, delayed care provision, and diversion from primary care contribute to the transmission of STIs? Sex Transm Infect. 2007;83(5):400-5.

28. Tanton C, Geary RS, Clifton S, Field N, Heap KL, Mapp F, et al. Sexual health clinic attendance and non-attendance in Britain: findings from the third National Survey of sexual attitudes and lifestyles (Natsal-3). Sex Transm Infect. 2018;94:268-76.
29. Dabrera G, Johnson SA, Bailey AC, Cassell JA. Do enhanced sexual health services meet the needs of men who have sex with men? Int J STD AIDS. 2013;24(3):233-5.

30. Richens J, Copas A, Sadiq ST, Kingori P, McCarthy O, Jones V, et al. A randomised controlled trial of computer-assisted interviewing in sexual health clinics. Sex Transm Infect. 2010;86(4):310-4.

31. Johnson AM, Copas AJ, Erens B, Mandalia S, Fenton K, Korovessis C, et al. Effect of computer-assisted self-interviews on reporting of sexual HIV risk behaviours in a general population sample: a methodological experiment. Aids. 2001;15(1):111-5.

32. Coleman L, Testa A. Experience of sexual intercourse and reported risk behaviour among an ethnically diverse sample of young people. Sex Health. 2006;3(3):169-77.

33. Gerver SM, Easterbrook PJ, Anderson M, Solarin I, Elam G, Fenton KA, et al. Sexual risk behaviours and sexual health outcomes among heterosexual black Caribbeans: comparing sexually transmitted infection clinic attendees and national probability survey respondents. Int J STD AIDS. 2011;22(2):85-90.

34. Clifton S, Mercer CH, Sonnenberg P, Tanton C, Field N, Gravningen K, et al. $\mathrm{STI}$ risk perception in the British population and how it relates to sexual behaviour and STI healthcare use: findings from a cross-sectional survey (Natsal-3). EClinicalMedicine. 2018;2:29-36.

35. Robertson R, Wenzel L, Thompson J, Charles A. Understanding NHS financial pressures. London: How are they affecting patient care? The King's Fund; 2017.

36. London Sexual Health Transformation Project: London Councils; 2016 [Available from: http://www.londoncouncils.gov.uk/our-key-themes/healthand-adult-services/public-health/sexual-health-0/london-sexual-health.

37. Aicken $\mathrm{CRH}$. Remote self-testing for sexually transmitted infections, within online care pathways: how could this intervention deliver public health benefit? Formative research using chlamydia as an exemplar: University College London; 2018.

\section{Publisher's Note}

Springer Nature remains neutral with regard to jurisdictional claims in published maps and institutional affiliations.

Ready to submit your research? Choose BMC and benefit from

- fast, convenient online submission

- thorough peer review by experienced researchers in your field

- rapid publication on acceptance

- support for research data, including large and complex data types

- gold Open Access which fosters wider collaboration and increased citations

- maximum visibility for your research: over $100 \mathrm{M}$ website views per year

At BMC, research is always in progress.

Learn more biomedcentral.com/submissions 